\title{
ON THE COMPACTNESS OF THE STEVIĆ-SHARMA OPERATOR ON THE LOGARITHMIC BLOCH SPACES
}

\author{
FANG ZHANG AND YONGMIN LIU
}

Abstract. Let $H(\mathbb{D})$ denote the space of all analytic functions on the unit disc $\mathbb{D}$ of the complex plane $\mathbb{C}, \psi_{1}, \psi_{2} \in H(\mathbb{D})$, and $\varphi$ be an analytic self-map of $\mathbb{D}$. In this paper, we characterize the compactness of the Stević-Sharma operator on the logarithmic Bloch spaces.

Mathematics subject classification (2010): 47B38, 47B33, 46E15, 30D45.

Keywords and phrases: Compactness, logarithmic Bloch space, multiplication operator, composition operator, differentiation operator.

\section{REFERENCES}

[1] R. Castillo, D. Clahane, J. Farías López and J. Ramos Fernández, Composition operators from logarithmic Bloch spaces to weighted Bloch spaces, Appl. Math. Comput. 219, 12 (2013), $6692-6706$.

[2] C. Cowen And B. MacCluer, Composition operators on spaces of analytic functions, Studies in Advanced Mathematics, CRC Press, Boca Raton, FL, USA, 1995.

[3] P. Galanopoulos, On $\mathscr{B}_{\log }$ to $Q_{\log }^{p}$ pullbacks, J. Math. Anal. Appl. 337, 1 (2008), 712-725.

[4] A. García Ortiz and J. Ramos-Fernández, Composition operators from logarithmic Bloch spaces to Bloch-type spaces, Georgian Math. J. 20, 4 (2013), 671-686.

[5] R. A. HibschweIler And N. Portnoy, Composition followed by differentiation between Bergman and Hardy spaces, Rocky Mountain J. Math. 35, 3 (2005), 843-855.

[6] O. HYV äRINEN AND I. NIEMINEN, Weighted composition followed by differentiation between Blochtype spaces, Rev. Mat. Complut. 27, 2 (2014), 641-656.

[7] Z. JIANG, On a class of operators from weighted Bergman spaces to some spaces of analytic functions, Taiwanese J. Math. 15, 5 (2011), 2095-2121.

[8] Z. JiAnG, On a product-type operator from weighted Bergman-Orlicz space to some weighted type spaces, Appl. Math. Comput. 256, 2015, 37-51.

[9] S. Krantz And S. STEVIĆ, On the iterated logarithmic Bloch space on the unit ball, Nonlinear Anal. TMA 71, (5-6) (2009), 1772-1795.

[10] S. LI, Products of weighted composition operator and differentiation operator on $H^{\infty}$, J. Math. (Wuhan) 30, (2) (2010), 212-216.

[11] S. Li And S. STEvić, Composition followed by differentiation between Bloch type spaces, J. Comput. Anal. Appl. 9, (2) (2007), 195-205.

[12] S. Li AND S. STEVIĆ, Composition followed by differentiation from mixed-norm spaces to $\alpha$-Bloch spaces, Sb. Math. 199, (12) (2008), 1847-1857.

[13] S. Li AND S. STEvić, Composition followed by differentiation between $H^{\infty}$ and $\alpha$-Bloch spaces, Houston J. Math. 35, (1) (2009), 327-340.

[14] S. Li AND S. STEvić, On an integral-type operator from iterated logarithmic Bloch spaces into Bloch-type spaces, Appl. Math. Comput. 215, (8) (2009), 3106-3115.

[15] Y. LIANG AND Z. ZHOU, Essential norm of the product of differentiation and composition operators between Bloch-type spaces, Arch. Math. 100, (4) (2013), 347-360.

[16] Y. LiANG AND Z. ZHOU, New estimate of essential norm of composition followed by differentiation between Bloch-type spaces, Banach J. Math. Anal. 8, (1) (2014), 118-137. 
[17] Y. LIU AND Y. YU, Weighted differentiation composition operators from mixed-norm to Zygmund spaces, Numer. Funct. Anal. Optim. 31, (7-9) (2010), 936-954.

[18] X. LIU AND Y. YU, The product of differentiation operator and multiplication operator from $H^{\infty}$ to Zygmund spaces, J. Xuzhou Norm. Univ. Nat. Sci. Ed. 29, (2011), 37-39.

[19] Y. LiU AND Y. YU, Composition followed by differentiation between $H^{\infty}$ and Zygmund spaces, Complex Anal. Oper. Theory 6, (1) (2012), 121-137.

[20] Y. LiU AND Y. YU, On a Stević-Sharma operator from Hardy spaces to the logarithmic Bloch spaces, J. Inequal. Appl. 2015, (2015) 2015:22, DOI 10.1186/s13660-015-0547-1.

[21] Y. LiU AND Y. YU, Products of composition, multiplication and radial derivative operators from logarithmic Bloch spaces to weighted-type spaces on the unit ball, J. Math. Anal. Appl. 423, (1) (2015), 76-93.

[22] Y. LiU AND J. ZHou, On an operator $M_{u} \mathscr{R}$ from mixed norm spaces to Zygmund-type spaces on the unit ball, Complex. Anal. Oper. Theory 7, (3) (2013), 593-606.

[23] K. Madigan And A. Matheson, Compact composition operator on the Bloch space, Trans. Amer. Math. Soc. 347, (7) (1995), 2679-2687.

[24] A. MonTES-RODRÍGUEZ, Weighted composition operators on weighted Banach spaces of analytic functions, J. London Math. Soc. (2) 61, (3) (2000), 872-884.

[25] S. Ohno, Products of composition and differentiation between Hardy spaces, Bull. Austral. Math. Soc. 73, (2) (2006), 235-243.

[26] H. QU, Y. LiU AND S. Cheng, Weighted differentiation composition operator from Logarithmic Bloch spaces to Zygmund-type spaces, Abstr. Appl. Anal., 2014, (2014), Article ID 832713, 14 pp.

[27] S. STEVIĆ, Generalized composition operators from logarithmic Bloch spaces to mixed-norm spaces, Util. Math. 77, (2008), 167-172.

[28] S. STEVIĆ, On a new integral-type operator from the weighted Bergman space to the Bloch-type space on the unit ball, Discrete Dyn. Nat. Soc. 2008, (2008), Article ID 154263, 14 pp.

[29] S. STEvić, On a new operator from $H^{\infty}$ to the Bloch-type space on the unit ball, Util. Math. 77, (2008), 257-263.

[30] S. STEVIĆ, On a new operator from the logarithmic Bloch space to the Bloch-type space on the unit ball, Appl. Math. Comput. 206, (1) (2008), 313-320.

[31] S. STEVIĆ, Integral-type operators from a mixed norm space to a Bloch-type space on the unit ball, Sib. Math. J. 50, (6) (2009), 1098-1105.

[32] S. STEVIĆ, Norm and essential norm of composition followed by differentiation from $\alpha$-Bloch spaces to $H_{\mu}^{\infty}$, Appl. Math. Comput. 207, (1) (2009), 225-229.

[33] S. Stević, On an integral-type operator from logarithmic Bloch-type and mixed-norm spaces to Bloch-type spaces, Nonlinear Anal. TMA 71, (12) (2009), 6323-6342.

[34] S. Stević, On new Bloch-type spaces, Appl. Math. Comput. 215, (2) (2009), 841-849.

[35] S. STEvić, Products of composition and differentiation operators on the weighted Bergman space, Bull. Belg. Math. Soc. Simon Stevin 16, (4) (2009), 623-635.

[36] S. STEVIĆ, Products of integral-type operators and composition operators from the mixed norm space to Bloch-type spaces, Sib. Math. J. 50, (4) (2009), 726-736.

[37] S. STEVIĆ, Weighted differentiation composition operators from mixed-norm spaces to weighted-type spaces, Appl. Math. Comput. 211, (1) (2009), 222-233.

[38] S. STEviĆ, On an integral operator between Bloch-type spaces on the unit ball, Bull. Sci. Math. 134 (4) (2010), 329-339.

[39] S. STEVIĆ, On an integral-type operator from logarithmic Bloch-type spaces to mixed-norm spaces on the unit ball, Appl. Math. Comput. 215, (11) (2010), 3817-3823.

[40] S. STEVIĆ, On an integral-type operator from Zygmund-type spaces to mixed-norm spaces on the unit ball, Abstr. Appl. Anal. 2010, (2010), Article ID 198608, 7 pp.

[41] S. STEVIĆ, On operator $P_{\phi}^{g}$ from the logarithmic Bloch-type space to the mixed-norm space on unit ball, Appl. Math. Comput. 215 (12) (2010), 4248-4255.

[42] S. STEVIĆ, Weighted composition operators from the logarithmic weighted-type space to the weighted Bergman space in $\mathbb{C}^{n}$, Appl. Math. Comput. 216, (3) (2010), 924-928.

[43] S. STEvić, Weighted differentiation composition operators from $H^{\infty}$ and Bloch spaces to $n$th weigthed-type spaces on the unit disk, Appl. Math. Comput. 216, (12) (2010), 3634-3641.

[44] S. STEviĆ, Characterizations of composition followed by differentiation between Bloch-type spaces, Appl. Math. Comput. 218, (8) (2011), 4312-4316. 
[45] S. STEVIĆ, On a product-type operator from Bloch spaces to weighted-type spaces on the unit ball, Appl. Math. Comput. 217, (12) (2011), 5930-5935.

[46] S. STEVIĆ, Norm of some operators from logarithmic Bloch-type spaces to weighted-type spaces, Appl. Math. Comput. 218, (22) (2012), 11163-11170.

[47] S. STEVIĆ, Weighted radial operator from the mixed-norm space to the $n$th weighted-type space on the unit ball, Appl. Math. Comput. 218, (18) (2012), 9241-9247.

[48] S. STEVIĆ AND R. AgARWAL, Weighted composition operators from logarithmic Bloch-type spaces to Bloch-type spaces, J. Inequal. Appl. 2009, (2009), Article ID 964814, 21 pp.

[49] S. Stević, A. Sharma AND A. Bhat, Essential norm of products of multiplication composition and differentiation operators on weighted Bergman spaces, Appl. Math. Comput. 218, (6) (2011), 2386-2397.

[50] S. Stević, A. Sharma And A. Bhat, Products of multiplication, composition and differentiation operators on weighted Bergman space, Appl. Math. Comput. 217, (20) (2011), 8115-8125.

[51] S. STEVIĆ AND S. UEKI, Integral-type operators acting between weighted-type spaces on the unit ball, Appl. Math. Comput. 215, (7) (2009), 2464-2471.

[52] S. YE, Multipliers and cyclic vectors on the weighted Bloch space, Math. J. Okayama Univ. 48, (2006), 135-143.

[53] S. YE, A weighted composition operator on the logarithmic Bloch space, Bull. Korean Math. Soc. 47, (3) (2010), 527-540.

[54] S. YE, Norm and essential norm of composition followed by differentiation from logarithmic Bloch spaces to $H_{\mu}^{\infty}$, Abstr. Appl. Anal. 2014, (2014), Article ID 725145, 6 pp.

[55] R. YonedA, The composition operators on weighted Bloch space, Arch. Math. (Basel) 78, (4) (2002), 310-317.

[56] Y. YU AND Y. LIU, The product of differentiation operator and multiplication operator from the mixed-norm to Bloch-type space (Chinese), Acta Math. Sci. Ser. A Chin. Ed. 32, (1) (2012), 68-79.

[57] Y. YU AND Y. LiU, On Stević type operator from $H^{\infty}$ space to the logarithmic Bloch spaces, Complex Anal. Oper. Theory, 9, 8 (2015), 1759-1780. DOI: 10.1007/s11785-015-0465-8.

[58] Y. YU AND Y. LIU, Boundedness of product-type operators on the logarithmic Bloch spaces, Chinese Journal of Contemporary Mathematics, in press.

[59] F. Zhang AND Y. LiU, Products of multiplication, composition and differentiation operators from mixed-norm spaces to weighted-type spaces, Taiwanese J. Math. 18, (6) (2014), 1927-1940.

[60] J. ZHOU AND Y. LIU, Products of radial derivative and multiplication operators from $F(p, q, s)$ to weighted-type spaces on the unit ball, Taiwanese J. Math. 17, (1) (2013), 161-178.

[61] J. ZHOU AND Y. LIU, Products of radial derivative and multiplication operator between mixed norm spaces and Zygmund-type spaces on the unit ball, Math. Inequal. Appl. 17, (1) (2014), 349-366.

[62] J. ZHOU AND X. ZHU, Product of differentiation and composition operators on the logarithmic Bloch space, J. Inequal. Appl. 2014, (2014), 2014:453, DOI 10.1186/1029-242X-2014-453.

[63] X. ZHU, Products of differentiation, composition and multiplication from Bergman type spaces to Bers type spaces, Integral Transforms Spec. Funct. 18, (3-4) (2007), 223-231. 